\title{
Farmers Engaged in Deliberative Practices; An Ethnographic Exploration of the Mosaic of Concerns in Livestock Agriculture
}

\author{
Clemens Driessen
}

Accepted: 4 September 2010/Published online: 18 September 2010

(C) The Author(s) 2010. This article is published with open access at Springerlink.com

\begin{abstract}
A plethora of ethical issues in livestock agriculture has emerged to public attention in recent decades, of which environmental and animal welfare concerns are but two, albeit prominent, themes. For livestock agriculture to be considered sustainable, somehow these interconnected themes need to be addressed. Ethical debate on these issues has been extensive, but mostly started from and focused on single issues. The views of farmers in these debates have been largely absent, or merely figured as interests, instead of being considered morally worthwhile themselves. In this paper the relevance for ethical debates of the ways farmers discuss and engage with moral concerns is explored. The variety of norms that figure in contemporary farming practices is sketched in its multifarious complexity, illustrated by ethnographic fieldwork, and systematized in terms of "orders of worth." Reviewing the practical arguments and commitments of farmers within this framework reveals that farming practices are subject to mixed motives, in which an amalgam of types of concerns play a role. Recognition of the peculiarly entangled nature of the ethics of farming practices could counter the tendency in policy making, technological innovation, and ethical thought to compartmentalize our moral landscape. Understanding farming practice as the integration of a mosaic of concerns in the light of a variety of moral experiences would foster public appreciation of positions of farmers in debates on improving the sustainability and societal acceptability of livestock agriculture.
\end{abstract}

Keywords Livestock farming · Farmers' ethics - Ethnography · Sustainability $\cdot$ Convention theory

C. Driessen $(\square)$

Applied Philosophy Group, Wageningen University, P.O. Box 8130,

6700 EW Wageningen, The Netherlands

e-mail: Clemens.Driessen@wur.nl 


\section{Introduction}

\section{Talking "Ethics" with Farmers?}

A casual conversation between for instance two dairy farmers might move logically from the weather forecast, the amount of rain since the "first cut" of grass, the health status of the cows, to preparations for the possible implications of climate change. And from interest rates, lending policies of banks, designs for new housingsystems, to milk prices, microbiological cell-counts, and breeding choices. Farmers typically do not discuss ethical issues in the way policy makers or professional ethicists tend to do. For instance "animal welfare" is not a subject likely to be discussed as such, or that one can easily start a conversation on in these terms. "Let's not lose sight of farmer welfare as well, shall we" is easily retorted. Does this mean that farmers do not care about the welfare of their animals, or only consider it as far as it is part of their productive concerns? Not necessarily, as this paper will argue. But in what way do ethical issues feature in farming practices and the discourse of farmers? How can we best understand the "ethics on the farm," the moral experience of farmers and their ethical choices? And in what terms could we engage in conversations with farmers on societal concerns situated on their farms?

\section{A Mosaic of Concerns}

Livestock farms have become the sites of numerous ethical issues that have gained prominence over the last decades (e.g., Kunkel 1984; Fraser 2001; Beekman 2008). A list of this mosaic of concerns would include: the supply of healthy and safe food of quality and taste; labor conditions and income of farmers and farm workers; rural livelihoods and regional economy; the wellbeing of farm animals; environmental conditions of water, soil, air, as well as effects on climate change and the health of local inhabitants; effects on nature and biodiversity; the depletion and efficient use of resources; aesthetic and cultural value of landscapes; concerns of global justice, food security and fair trade; and the accessibility or traceability of agricultural production to the public. One salient feature of this list is the sheer diversity of types of concerns that are involved. Furthermore, for each period in time, for each country or even region, and for each agricultural sub-sector, the formulation and perceived significance of these concerns will be different (cf. Jensen and Sørensen 1999). Whether they feature as societal problems, market externalities, or are taken up as the multiple aims of agricultural practice, deliberations on their meanings are situated in distinct arenas. What is fairly universal though, is that increasingly these issues are moved from the sphere of farmer discretion to that of public policy and market choice (cf. Rollin 1995; Meijboom 2009). Many of these concerns, such as animal welfare and environmental degradation, have developed into separate policy fields and accompanying scientific disciplines. Ethical analysis and theorizing regarding these fields has developed as well, offering a variety of "sources" of values, and arguments on the types and severity of the obligations these entail. At the same time though, these issues can be considered to be in many ways interrelated (e.g., Korthals 2001; McGlone 2001; Appleby 2005; Constance 2009); 
which makes more encompassing perspectives on the practical ways of dealing with the mosaic worthwhile to explore.

\section{Farmer Ethics}

The perspective from "practice," of farmers themselves, has remained rather mute in public discussions. Apart from occasional fierce outcries and forceful lobbying to further their perceived interests, little debate has emerged on the visions of farmers regarding the public concerns situated on their fields and in their barns. Nor are they easily considered to have a (collective) professional ethics (Meijboom 2009). Sociological studies of (types of) farmers have yielded a diversity of coherent and internally rational farming styles (Van der Ploeg 1999). This typology can be extended and linked with categorizations in terms of value orientations, or fundamental moral attitudes (Cohen et al. 2009). In this paper this kind of systematic categorization of types of farmers and their ethical stances is not the aim. Even though these labels may be found to explain positions of farmers regarding ethical debates, they also may function as shortcuts to actually having to speak and listen to them. Rather the goal here is to explore the forms that ethical considerations take in farmer decision making, and the ways in which ethical concerns feature in a variety of farmers' practices and discourses. By elaborating concepts to interpret the breadth of moral experiences of contemporary (Dutch) livestock farmers, the aim is to enliven ethical debates on their practices, and to make their considerations amenable for critical public discussion in terms that are meaningful to them. Several characteristics of the way farmers encounter concerns depart from contemporary societal ways of dealing with ethical issues. This makes that the ethics professed by farmers is at odds with the modern moral landscape. By increasing the understanding of contemporary farm life among policy makers and the general public, room could be created for farmers to more actively and sophisticatedly join debates on environmental concerns, nature conservation, animal welfare, and (even) the global impacts of livestock farming. With an appreciation of their publicly debated "ethical room for manoeuvre" (cf. Korthals 2008) we could move away from the adversarial and entrenched oppositions that often characterize these discussions (Fraser 2001), if they take place at all.

\section{Outline}

In the next section, three ways of approaching the mosaic of ethical concerns are distinguished: principlist ethical theories, technological optimization, and a pragmatist and ethnographic approach to ethics. In section three, some theoretical backgrounds to this last approach will be elaborated, and the way situations were sought to study ethnographically the discourse and practices of farmers will be explained. Section four describes the peculiar nature of farming practices vis-à-vis common modes of ethical theorizing. To systematically chart the mixture of moral motives in the practice of farmers, in section five a sociological model distinguishing justificatory regimes is explained, and used to interpret the fieldwork. After this, in a short intermezzo, the farmer's approach of concrete ethical issues is illustrated by an example from dairy farming: dehorning cows. Finally, some 
implications of this understanding of farmers' ethics to the analysis of ethical concerns and public deliberation are discussed.

\section{Three Approaches to the Mosaic of Concerns}

There is a variety of ways in which the ethical concerns in livestock farming could be understood and dealt with. Here, three kinds of approaches to farming issues are distinguished.

\section{Principlist Ethics}

Most classical ethical theories that are applied to discuss animal farming are attempts to reduce issues to a single moral principle, usually either the pleasure and suffering of (human and animal) sentient beings, in utilitarianism, or respect for living subjects, in rights theories. Pluralist approaches to dealing with ethical concerns acknowledge the importance of multiple principles, most commonly: beneficence, non-maleficence, autonomy, and justice. This type of analysis, which originated in medical ethics (Beauchamp and Childress 1994), has been adapted to fit the needs of analysis of issues in animal husbandry (Mepham 2000). The advantage of this approach is that there is room to systematize the complexity of concerns and formulate "dilemmas" in dealing with these. The mosaic of concerns can then be taken to be the site of tragic choices, for instance between consumer autonomy and animal well-being, or as trade-offs between farmer safety and the intrinsic values of animals. These conflicting concerns in this pluralist approach can be charted in terms of non-reducible principles. However, these principles by themselves provide no definite way to decide on them. ${ }^{1}$ If applying ethical theories in itself then is not enough to "solve problems," the question arises whether principles derived from theories are the best, and only, searchlight for getting at the complexities of moral choices. Furthermore, a focus on ethical dilemmas could run the danger of turning dynamic innovation and regulatory processes into static situations for moral appraisal; thus reifying existing practices instead of opening up possibilities for creatively developing win-win situations.

\section{Technological Optimization}

A second approach does not consider the mosaic of concerns to be a terrain for ethical debate, but rather for scientific research and technological innovation (cf. Rollin 1995; Fraser 1999). The mosaic here is taken as a list of variables to be optimized in complex systems. An extreme example of this approach can be found in proposals to create integrated "agro-production parks" in which, within a closed "industrial ecology," large scale pig breeding and fattening could be combined with biogas

\footnotetext{
${ }^{1}$ Even though ethical analysis in terms of principles can be instrumental in broadening the understandings of ethical concerns in societal debates. Especially when apending principled ethical theories with participatory approaches, these can provide ways to guide decision making on societal issues (e.g., Kaiser and Forsberg 2001).
} 
production and fish breeding (e.g., De Wilt et al. 2000). The benefits of the projected huge scale of this type of facility, preferably situated in a sea port, would be utilized to reduce emissions and increase the amount of space per animal. And a slaughterhouse within the facility would preclude the need for transporting live animals. This proposal, though potentially offering a solution to a number of pressing issues of animal welfare and environmental emissions, did overlook concerns that could have come up in the principled ethical approaches; for one thing the parks may mean a stark decline of "farmer autonomy" (cf. Driessen 2007). This type of schemes (in public media in the Netherlands labeled "pig towers" ["varkensflats"]), that focus on large scale forms of innovation in dealing with these issues, have been shown to give rise to severe public resistance and lack of trust (e.g., Hoes et al. 2008). Meanwhile, taking the mosaic of concerns as mainly a technological challenge for producing winwin situations can be misleading and short sighted, as ethical choices on priorities and ideals would still be part of the process.

\section{Ethics by Engagement in Practice}

The two modes of dealing with the mosaic of concerns sketched so far have in common that the issues are addressed as if they require an understanding from a single vantage point. Whether it is by means of ethical analysis and public deliberation, or scientific research, engineering, and design, the ethical decision (-making process) is implicitly thought of as centralized and generic. Even then, the perspective of farmers, who in their daily practices somehow try to integrate (or circumvent) the mosaic of moral demands, can be relevant. For instance by providing an insight into the practicality and feasibility of the ethical solutions (Birnbacher 1999).

An alternative approach to ethical concerns is one in which the empirical research is not merely part of an effort to solve ethical puzzles that are basically considered to be those of an altruistic and all-knowing collective agent. That alternative would be a conception of ethical thinking that considers the world as populated with a variety of moral actors. ${ }^{2}$ This approach is more likely to help motivate farmers to be "ethical," by granting the opportunity to develop and follow their own rationality. Instead of forcing a choice between solving principled dilemmas or searching for technical winwin solutions, the focus on practice means publicly engaging in a continuous combination of deliberative trade-off and experimental learning. ${ }^{3}$

\footnotetext{
2 This means not a mere focus on the autonomy side of the pluralist ethical approach. In farmers' decisions and in public deliberations the full spectrum of ethical principles in some form can come to the fore.

3 There have been numerous research projects to design sustainable farming systems that actively involve farmers (e.g., Bos 2008). And agricultural research, especially within the organic sector, has a tradition of studying issues in collaboration with farmers, and to include their viewpoints and experiences (e.g., Waiblinger et al. 2000). Also farmers themselves have set-up local initiatives for technological and institutional ways of dealing with a variety of concerns (e.g., Eshuis and Stuiver 2005). But these are mostly not explicitly understood as involving ethical choices and trade-offs. The third approach here is not meant in opposition to these efforts, but to highlight ways of actively dealing with ethical concerns within them. While the general thrust of public debate and policy making with regard to these issues is aimed towards generic regulations and top-down decision making.
} 
Not all ethical concerns are best dealt with by merely granting an ethical "license" to the farmer to do as he or she pleases. Sometimes strict governmental regulations or market standards are required to help farmers to remain competitive while improving their practices, or to make them reconsider ingrained practices that have come under scrutiny. But farmers can agree on this, and discussing their practices in terms of an ethics that is sensitive to the changing character of systems and norms would contribute to an increased reflexivity on the farm.

\section{Researching Ethics by Doing Fieldwork}

\section{Ethics and Ethnography}

Apart from prudential reasons to involve those in the field in ethical debates, listening to farmers as an approach to ethics can be argued for because it is important to retain concepts and search for arguments that do not stray too far from actual moral experiences and motivations of people. In order to prevent us from "losing our concepts" (Diamond 1988), the role of ethics then is to explore and develop rich accounts of our moral universe. An understanding of the nature and role of ethical thinking that is considered to benefit from engaging with practices can be found within the tradition of pragmatism. There, both knowledge of the world, and an ethical stance in it, are considered to result from active experience, since people are always embedded in a particular environment (Light and Katz 1996). Ethics therefore is to be found in culture, which is not to be understood as an "add-on" to material reality, but as constitutive to understanding, in which the symbolic and the material are integrated (Geertz 2000). With personal experience and the meaning of context as the focus of ethical inquiry, anthropological fieldwork is an appropriate form of empirical study of ethics. An ethnographic engagement with practices can help to bring some of the "messy heterogeneity of being in the world" into ethical discussions (Whatmore 2002). Central distinctions in ethical thought, such as between nature and culture, and the social and the material, can then be explored as shifting ground, rather then assumed to be stable and unproblematic norms to assess farming practices. Especially in our technological culture, having an eye for the co-evolution processes of material practices and normative stances is central to developing an ethical understanding of problematic situations (Keulartz et al. 2002). The aim of fieldwork is then to yield a focus of ethical analysis not solely concerned with values that are expressed discursively, but also with material and embodied ways of dealing with ethical concerns that are of a relational and experiential character. And studying what happens in the field would grant a view on the ways in which the moral agency of farmers emerges from material arrangements and the behavior of animals (cf. Higgins 2006). Then, besides farmers, also animals are not considered as generic moral patients, but through their individual behavior may play an active part in ethical learning processes. ${ }^{4}$

\footnotetext{
4 These include not only the farmed animals, but also wild animals living on farms, such as meadowbirds and their predators: Many farms participate in schemes to protect nesting meadow birds of endangered
} 
How to Study Ethics in the Field

Now that it is clear that we need ethnographic accounts of the discourse and practices of farmers, how to go about studying these? Where, for instance, was the author during the conversations sketched in the introduction? Interviewing farmers on their "ethics" proved to be difficult, especially as farmers tend not to see the advantage for their practice of discussing ethical theories (Driessen 2008). Instead, for this paper the author has sought and arranged situations in which farmers explained their practices and justified their choices within farming peer groups. This was done by participating in a weeklong practical training course for young dairy farmers, together with a group of agricultural university students; by accompanying animal science researchers on farm visits; by joining in meetings of dairy farming networks aimed at dealing with practical concerns; and by arranging excursions to innovative farmers with mixed groups of vocational and academic students of agriculture. ${ }^{5}$ The fieldwork was set up as moving from passive, non-directive, studying of farmer discourses and practices, to more active forms of presence and questioning. At these various occasions, the arguments and behavior of farmers and (farming) students were observed, and preliminary findings and interpretations discussed with them, asking for further explanation and justification of their views and practices, while explaining the purpose of researching "their ethics."

\section{Farming as a Matter of Mixed Motives}

In what way do the moral understandings of farmers diverge from ethical theorizing, and what should we look for in the "ethics of farmers?" Where most ethical theories distinguish self-regarding from other-regarding concerns, while demarcating ethics as concerned exclusively with the latter, this seems a particularly ill-equipped mode of thinking about farming. Though in some instances pointing at purely selfregarding motives has critical force (e.g., when animal welfare is defined purely in terms of productivity), a more ambiguous type of ethical thinking is required to

\footnotetext{
Footnote 4 continued

varieties. Volunteers mark the nests of of these birds so farmers can mow around them. However, predators tend to find out about the meanings of the flags in the field, and use these to find their prey. Farmers and volunteers have been searching for new ways of indicating nests in order to prevent this.

5 All in all, the number of farmers that were visited, or somehow interacted with, was about fifty, in various degrees of individual encounters and depth of talks. About the same number of vocational students (in three weeklong excursions) of different educational levels was spoken to, most of whom had a farming background, worked on a farm, and planned to take over the parental farm. The study is confined to Dutch farmers, mostly dairy and pig farmers, with a few poultry (laying hen or broiler) farmers. The farmers were predominantly male, though many of the farms were of the "maatschap" (partnership) legal format and included an active role for women; about six of the farmers and about thirteen of the participating students were female. An effort was made to interact with a variety of types of farmers, though an emphasis was on more "innovative" ones who experiment with new practices and techniques; Organic (and perhaps somewhat "eccentric") farmers are likely to have been overrepresented. This paper not so much aims to be "representative" of farmers in general, but rather to propose ways of discussing farm practices that connect to the experiences and outlooks of farmers who are explicitly reflective and willing to engage in forms of public deliberation.
} 
connect to the intricate nature of farmers' motivations, and contributes to the search for improvements of elements of the mosaic that are not directly offset by losses in income.

The activities of most farmers are not completely guided by concerns of efficiency and profit, not even those in highly intensive sectors such as laying hen and pig farming. In farm visits, these "mixed motives" can be encountered at many points, for instance in the relations to animals. The morality of their motives is most salient at moments when farmers diverge from what is economically required. Then there are clear instances of moral concerns, such as when cows are given expensive treatments even if production standards would require them to be culled, or a sow is kept one more round even though she is expected to have become not productive enough anymore. Here the ethical appears as the irrationalities that stand out from a perspective of pure economic rationality. And farmers talk of feelings of sadness when animals die: "You sometimes do get a bond with a certain cow, and experience a sense of loss, even mourning, when she dies. I even know of a farming family that has a picture of their favorite cow framed in their living room. But that goes a bit far I'd say." Or farmers may exhibit forms of coping behavior, as related by a sow farmer: "Sometimes a sow dies a few days before she is due to deliver. It is not economically sensible to perform a caesarean on a sow, most vets have never even performed one. But next time a sow dies I'll go and take a walk, rather than stay and watch the unborn piglets suffocating in their dying mother." Clearly, the emotional attachment is more prevalent with animals that live longer and are kept in smaller numbers-more with dairy cows than fattening pigs or broilers and hens. But still, in most farmers some of this sensitivity seems to exist. Often this is explained in terms of reciprocity, of justice towards animals that have produced a lot, or of a personal relation with an animal that behaved good natured towards the farmer. But occasionally also just in terms of "fun": "Sometimes, in the new laying hen housing, I just go and sit on the floor, and they will come and climb and sit on top of me."

When looking for ethics in farming, the focus thus easily goes to irrational moments at which farmers do something against their productive interests. These irrationalities and inefficiencies can be a way for farmers to gain some sympathy, or even legitimacy, in the eye of the general public, as caring not just for money, but also for animals, nature, and the environment. But situating the ethics solely in these exceptions to the productionist rationality implies a portrayal of animal farming as basically unethical. To grant farmers a serious ethical stance requires an appreciation of their central aim: the efficient production of food (Thompson 1995). Then, what in the eyes of outsiders appears as a double attitude towards nature and animals, for farmers is a coherent practice. Even in their bodily way of approaching animals, this hybrid relation can be seen at work. Cows are stroked at the same time in a caressing and measuring way. The touch estimating stomach movement or bone structure can morph into a pat on her back. In this way the ethics of farmers is performed in their bodily locomotion and interaction with their animals. The ease of handling a chicken, of picking it up and tucking it gently under one's arm, can be accompanied by another swift movement of holding it by its feet, and proudly, if somewhat reluctantly, indicating the way one could pull the head off 
in a single movement. This ambiguous way of relating to animals might come across as inconsistent, or even disturbed, especially to someone unfamiliar with the realities of farm life. This hybridity (or perhaps "monstrousness") of moral relations to animals is most clear in case of traditional farming practices. Before modernization took hold, the moral universe of the farmer was-even though comprised of a complicated set of relations-experienced as self-evidently coherent (Harbers 2002). But also contemporary farmers mostly do not experience tensions between say hi-tech machinery and ideals of naturalness, e.g., regarding milking robots.

\section{Regimes of Justification as a Model to Draw out the Moral Complexity of Farming Practices}

\section{Orders of Worth}

In order to appreciate the variety of types of concerns and gain a systematic understanding of the hybrid perspective of farmer ethics, the mixed motives of farmers can be portrayed in terms of the "orders of worth" in the framework of practices of justification as developed by Boltanski and Thevenot (1991). They offer a model to study the kinds of justifications people produce for their actions, drawing on both fieldwork (mostly on labor relations in large French organizations) and classic works of political philosophy. ${ }^{6}$ They distinguish six types of common justificatory grammars or regimes: The worth of inspiration, in which value is derived from creativity, holiness, emotion, and imagination. This is how the production of art is understood, personal experience is lived through, and visions are developed in spite of the opinions of others. In the domestic order a normative grammar is common in which personal relations of trust, kinship, face to face encounters, self sacrifice, and tradition are valued, and where a sense of place is important. The regime of renown is all about honor, recognition, the opinion of others, and public display of success. The civic order comprises a type of arguments that relate to (some understanding of) a common good, such as in terms of equal rights, or solidarity. The market regime is coordinated by contracts between consumers and producers, and is focused on mediating scarce goods. Appreciated are entrepreneurs that seize the opportunities offered by the market. In the industrial world, worth is based on efficiency in the production of material goods. Professional capabilities of experts are valued, their organizational planning and investing to increase productivity.

\footnotetext{
${ }^{6}$ With this model for empirical research, convention theory offers a way to take seriously the agency and justifications of actors, while also allowing for the existence of (performed) forms of universality. Thereby creating a middle ground of conceiving agency, between technological or structural determinism and ideal autonomous ethical agents.
} 
All these domains can be a resource for actors to make (generalizing) claims, to debate public issues, and to evaluate situations, persons, or objects, by interpreting their relevant aspects. ${ }^{7}$ Disputes in practice can arise over the legitimate criteria to judge an action or a situation, as humans have the capacity to criticize the type of arguments produced by others in a specific situation. ${ }^{8}$

These six modes of evaluation are not to be understood as the full range of possible justificatory logics. For instance a "green" order of worth was later added, describing the type of arguments found in discussions over environmental concerns. And cultural differences may exist in the meanings of orders and their relative importance (Boltanski and Thevenot 1999; Lamont and Thevenot 2000). ${ }^{9}$

A number of authors have applied the orders of worth to study struggles and debates within agriculture (e.g., Marsden et al. 1996; Busch 2000). The framework can be used to describe differences and strengthen oppositions: between organic and commercial; between high tech and traditional; between bulk production and quality; and between commercial and idealist organic farmers. Rosin and Campbell (2009: 40) point at the complex ways in which contradictory justifications are negotiated and combined in the development of organic agriculture. In this paper, the orders are used not to differentiate farmers, but to explore the intricate ways that various norms operate in farming practices.

\section{Farming in Multiple Orders of Worth}

Of course productivity is one of the central values of farming, often valued for itself (industrial), or in connection with producing abundant and affordable food for humanity (civic). Farm animals such as cows and pigs are valued for being efficient, and practical farm choices are mostly described as "management" by farmers and others in the sector. Thereby farm practices are positioned squarely in the industrial

\footnotetext{
7 As an example of how arguments on an issue can be drawn from these various orders, one could focus on our ethical concerns over animals: Farmers could be convinced to improve the treatment of their animals in order to raise their productivity and lower costs (industrial), or they could be motivated to do so as a business opportunity, by gaining a higher price for welfare labeled products (market). We may be inclined to want to treat animals humanely based on experiences of caring for our pets and having personal relations with animals (domestic), or due to celebrities that campaign for the ethical treatment of animals (renown). We may as well be convinced by activist groups arguing for the institutionalization of animal rights (civic), or we may have had a life changing experience after encountering in the wild a whale, dolphin, elephant, or another "honorary primate," or hold a religious conviction that requires reverence or duties towards animals (inspired).

${ }^{8}$ Not always do people engage in justificatory explanations for what they do; some societal processes are contingent, sometimes people make private arrangements outside of these orders, or various forms of power are exercised without justification.

9 The orders can be understood in a variety of ways. When taken as a model for studying controversies, the orders form a "moral geography" in which the types of arguments can be charted that play a role in practices and conflict resolution. Or it can be used as a framework for developing critical arguments internal or external to an order. When the types of justifications are taken to be incommensurable normative paradigms, the model can even function as an approach to resolve issues, through determining the appropriate order for each situation. Used in that way it would resemble the theory of spheres of justice of Michael Walzer (1983). There the different domains correspond with institutions, such as political, market, love, and religious institutions, which are each organized according a single societal principle. (cf. Lamont and Thevenot 2000: 6).
} 
order. Sustainability can also be understood partly within this order, as the resource efficient production of food.

The market order is also central to the understanding of farming, while getting an adequate price for the produce is a prerequisite to continue farming. Nevertheless, markets for agricultural products are notorious for not being "true markets," for being highly regulated, organized, monopolized, and subsidized. "Money is a necessary evil; if you want to become rich you should not become a farmer; all the money we make we use to invest, or to pay off bank loans." Farmers nevertheless may operate as entrepreneurs, also in seeing the market value of other elements of the mosaic, such as "green services" for nature conservation that are paid for by the government.

Farming practices are also situated in the domestic realm. It is common among e.g., dairy farmers to ask "how many cows do you have at home?" when discussing someone's farm, as they predominantly still live next to their production facilities. And in the architecture, also of comparatively large stalls, an effort is made to create an ensemble that conveys a rural image and connects to regional architectural traditions. In a discussion the author had with farming students, these contested the use of the (in their experience derogatory) term "industry," even for comparatively large scale farming operations: "What does it matter whether a farmer has a hundred or 300 cows, it is still a farm." "But what if the farmer no longer lives next to the production facility?" "Well..., yeah, maybe then it would be industrial." When introducing themselves and their "business" ["bedrijf"], they typically start with an account of the family situation. Also the importance of reproduction of animals, and production of food, allows their practice to be situated not only in the industrial but also the domestic order. This becomes most clear when the aim of many farmers is revealed: to continue farming and handing down a viable farm to the next generation.

Interesting mixtures of justificatory worlds come together in practice. When farmers mow their fields many will try to avoid hitting birds nests. Not only for the premium they might get (market), but according to several farmers also motivated by a concern for rare species (civic), and to avoid the cruel experience of crushing animals (domestic or inspired). Farmers notice the need for a multiplicity of orders to increase legitimacy (public as well as private) of their practice. A pig farmer explained: "With our new sow-stall with group housing, the children are willing to enter the barn again, which they refused when we had the confined system." This made the productive area of the farm part of the household again, and also created the potential of one of the children to be willing to take over the farm in due time. Apart from these elements from the domestic realm, the view of (young) children is taken as of special value within the inspirational regime (Boltanski and Thevenot 1999: 370), creating a renewed sense of legitimacy of the farming practice in that respect.

Pig farmers are often keen to explain the variety of origins of the feedstuff they manage to gather, while this type of legitimation of pig farming as efficient and sustainable has become problematic due to the issue of hygiene and food borne diseases (cf. Law and Mol 2008). "Feeding wet mash feed is a challenge, in terms of economic margins and for optimizing the feed, keeping the pigs healthy, and 
maintaining the taste and quality of the feed. We often use side-products from the human food sector; it is not waste disposal, but it serves to solve a problem; Last year, we received 2500 tons of bread from the Ruhr area, in batches of 50 tons fresh from the previous day. My wife and I, standing in the kitchen, at times found this mountain of bread in the courtyard a troublesome sight. While elsewhere in the world people are starving, here we throw away bread that is still good to eat." It might very well have been the domestic nature of the shared view from the kitchen that brings this moral perspective home to the farmer (civic, through domestic). The processing of waste-flows in a more industrial setting is likely to be considered far more "normal," when compared to the bread that is clearly out of place in their backyard. At the same time the farmer is proud of, or at least content with, how he manages to keep feed costs low, offer a varied diet to his pigs, and works to recycle waste flows from the food industry and thereby adds value (industrial and market).

One could ask why we should bother that farmers also can somewhat love their animals and care for their land; how it matters that farmers have ethical sensitivities beyond their immediate tasks. But the practical nature of farm activities makes their ethical views relevant to changes in practices. Especially the more entrepreneurial farmers can exhibit a form of ethical agency by creating new ways of dealing with societal concerns. One example would be the investment in alternative modes of energy production by erecting windmills or biomass installations. These initiatives are ways of expressing ethical commitments that can be situated both in market (entrepreneurial), civic (common good), and industrial (efficiency) orders. Of course these initiatives are often taken as part of wider subsidy schemes and market arrangements. But rather than situating all important ethical developments on the policy level, some of the moral agency could very well be located at farm level initiatives (cf. Roep et al. 2003).

A number of both organic and non-organic (whether conventional, or selfproclaimed "in between" or even "beyond organic") farmers stated that organic is "also merely another set of rules." By thus creating an external position to the organic standards, they created "room" for professional autonomy, a knowledgeable position from which to develop a farming practice that is rational in their eyes without slavishly following (external) rules that in some situations can be viewed as irrational and overly, or too little, stringent. Thus these farmers create a way of affirming their more "rational" (industrial) outlook but also a more lived-through farming ethic they developed by themselves, connecting to the inspired order of authenticity and creativity.

\section{The Moral Landscape of Farming vs. Compartmentalized Ethics}

Farmers experience their mixed motives and the variety of moral orders mostly not as a hybrid; their practices appear as such only within and when compared to functionally specialized and morally differentiated institutions. When in the theory of Boltanski and Thevenot the orders of justification are considered basically incompatible, farming appears as an ethical chaos. The central issue for understanding the moral landscape of farming is then whether the orders can be 
legitimately "mixed" in a single practice, rather than merely cohabit in uneasy compromise.

In our modernized and functionally differentiated society, these orders tend to become separated and roles and relations specialized and purified. ${ }^{10}$ As localized activities, these moral orders are even spatially planned, thereby institutionalizing and effectively constructing a zoning of types of appropriate normative arguments and possible relations between humans and between humans and animals. ${ }^{11}$ Areas are designated for (industrial) production, for (inspiring) nature and recreation, or for (domestic) habitation. This type of ethical thinking that resists ambiguity is exemplified by the design of the pig tower and responses to it: as a reaction to the proposal unwittingly a coalition emerged of those that felt that "pigs should be on a farm" and others that claimed "pigs don't belong in a factory." Concrete plans for large scale pig farms more recently though met fierce resistance from local inhabitants, stating "this belongs in an industrial zone." With the industrialization of agriculture, the ethical issue comes down to sorting out where an activity belongs in our discretely zoned moral landscape.

When assessed from each single moral order, current practices seem deficient and suboptimal. Most farmers are not fully entrepreneurs, nor are they the best imaginable nature managers. Much of contemporary farming in the Netherlands still is a peculiar amalgam of modernity and tradition, of material production at home, of hi-tech efficiency and relations of care (cf. Meijboom 2009). With farming understood and arranged as a focal practice in which these various aspects are combined, productive work can be an adequate response to place (Thompson 2000), rather than a NIMBY activity in search for a wasteland. For this an intricate combination of modes of critique would be required to appreciate dealing with farming concerns.

\footnotetext{
${ }^{10}$ Of course there are a variety of other institutions where a mixture of orders of worth are necessary to understand their meaning and practices; think only of the (ideal of the) university, which comprises industrial (producing knowledge workers), market (adding value, spin offs of research), inspired (creativity, self actualization), domestic (campus, modeling teacher student relations on patriarchal, or matriarchal, ideals), and civic (educating autonomous and responsible citizens, doing research for the betterment of humanity) orders of worth. But here as well it can be argued that industrial (output measurements) and market norms (increasing numbers of students and tuition fees, and meeting the market demands for workers) are increasingly dominant.

${ }^{11}$ Regarding the orders of worth and our dealing with animals it is clear that our motives and justifications for certain treatments of animals are varied, but also that in modern society there is a tendency to separate these understandings of animals over different human animal relations and societal domains. Animal practices and the attending relations and meanings can then legitimately only be of one kind, and farming is no longer one of these "singular" practices (cf. Korthals 2001; Harbers 2002).
} 
An illustration of ethical decision making as practical engagement: cow horns

Should cows have horns, or is it permissible to dehorn them? That is the type of question an agricultural ethicist might try to answer, and that would be prone to become subject of governmental regulation. (And it is a good example of a complex, multi-factorial issue that is best studied by involving the views and experiences of farmers, as there have been some efforts in the past (Waiblinger et al. 2000; Baars and Buitink 1995).) The issue could be considered to be a technological challenge: of a method for painlessly dehorning, of designing housing that is suitable for horned animals, or of breeding cows without horns. Alternatively, one could argue dehorning to be a case to be decided in the ethical terms of "bodily integrity" of the cow, dismissing this mutilation of the animal based on her (civic) right, or perhaps (inspirational) essence. But when taken up solely from these angles, several aspects would not be discussed. On a farm visit with agricultural students, a farmer explained: "Cows with horns offer little trouble, as long as the housing is in order. With our large round and open housing, the weakest animal in the herd can flee; in loose (box) housing you sometimes see that an animal can be totally butted to pieces [helemaal kapotgestoten]. Then you'll see blood in the milk from the fighting; this we see only a few times a year." There is some grumbling talk among the attending farming students. "Why do you want to have horns?" "We do not believe horns are "antennas to the cosmos" or anything like that. But we do believe that horns play a role in their digestion system, that it improves their health. And look, we think it's beautiful." When the tour moves into the field, the cows come walking towards the large group of visitors and mingle with them. "You see these cows are clearly not afraid, but curious. When they see people they come and take a look." The students start goofing around with the cows, playfully trying to catch their horns. But most feel retaining the horns at their own farms to be too dangerous, to the farmer and to the other cows. Whether the housing is adequate to prevent horned cows hurting each other depends on the skills of the farmer, but is also a matter of accepting some level of mutual damaging of cows (cf. Baars and Buitink 1995), whether in terms of loss of productivity (industrial) or as a relation of responsibility and care of the farmer for individual cows (domestic). Decisions on dehorning include numerous choices: for a type of behavior and character of the cows and a certain kind of herd, a type of human-animal relation (as domestic patriarchal, or inspired and respectful), an estimation of the risk to the farmer, an aesthetic appreciation. These interconnected choices farming abounds with are not easily decided outside of the particular situations in which farmers find themselves, and the multiple orders from which to evaluate their practice, as they ultimately come down to the question of what kind of farmer to be.

\title{
Implications of the Sketch of Farmer Ethics for Deliberations on Sustainability
}

\author{
Public Debate Infused by Farmer Experiences
}

What do the ways in which farmers experience and express the ethical aspects of their practice mean for debates on sustainable agriculture? The descriptions of farmer motives in terms of orders of worth revealed implicit positions on the types of moral arguments that can or should be part of public deliberation. When farmers and their views are not obviously included in these debates, or if the ability of farmers to take part in ethical debates is questioned, a choice is already made on whose terms these debates are to be performed, and what constitutes legitimate arguments and a meaningful debate. Recognition of the peculiarly entangled nature of the ethics of farming practices could counter the tendency in policy making, technological innovation, and ethical thought to compartmentalize our moral landscape. Understanding farming practice as the integration of the mosaic of concerns in the light of a wide variety of moral experiences would foster public appreciation of the mixed motives of farmers. Rather than try to fit them into the 
mould of ethical theory that purifies self-regarding from other-regarding motives and situates all meaningful ethical concerns in the latter. With the "selves" of the farmers and their families considered as part of the meaningful context of local practices, ethical debates would include a variety of experiences and considerations, and include embodied ways of interacting with animals, food, agricultural nature, and the environment. Then it is clear that the mosaic of concerns requires ethical responses from a variety of orders of worth, and that the mixed motives of farmers offer a relevant outlook on this mosaic.

\section{Ethics as Reflexivity in Practice}

The envisioned outcome of deliberations does not need to be a single generic conclusion, a collective decision on what is the right way to practice sustainable agriculture. The variety in circumstances and skills of farmers can be taken as legitimating a diversity of ways to integrate the mosaic of ethical concerns they grapple with (cf. Kupper and De Cock Buning 2010). The case of dealing with horns illustrates that for instance defining animal welfare is not necessarily best completely relegated to a centralized policy making process, based solely on scientific expertise and abstract reductionist ethical analysis. Farmers in practice can use the variety of motives and concerns to creatively and reflexively learn to develop a system in which issues are dealt with. This could be considered an argument in favor of institutional and regulatory reform so as to create more "ethical room for manoeuvre" (Korthals 2008), creating incentives for farmers to pursue and discuss their own strategies. Farmers are mostly able to explain their particular choices and arrangements, and by engaging in public discussions find occasion to further reflect on these. The task of the public would then be to critically follow their endeavors; with professional ethicists interpreting and developing the concepts to reflect on the collective experimental learning processes. This might mean that things will not always be optimized and rationally weighed in terms of stakeholders and values by policy makers and ethics committees. But allowing a space for farmers as moral subjects, acting from their own rationalities and skills in interaction with their products, land, and animals, will make conversations with them more interesting. Farmers meanwhile will need to show to the public why it should want to prevent their disappearance as (independent) moral subjects, gain a critical perspective on existing practices and technologies, and open up their local and contextual learning processes for public deliberation.

Acknowledgments The author in researching and writing this paper owes special thanks to: Michiel Korthals, Volkert Beekman, Henk van den Belt, Marc Bracke, Hans Spoolder, Leonie Heutinck, Carola van der Peet, Anita Hoofs, members of the Weide-robot network, Steven Vrielink, Zwier van der Vegte, Henri Holster, Frank Lensinck, members of the Oost-overijsselse melkrobot netwerk, de Melkveeacademie; Teachers and farmers at PTC + Oenskerk, Lars Keizerwaard, Douwe Kappers, Sanne van den Dungen, Maarten Kea, Wanka Lelieveld, Barbara Tielemans, Harmen Riphagen, Hein Klaasen, Florien Kuyper, Egbert Lantinga, Peter Groot Koerkamp, students of HAS Den Bosch and CAH Dronten, Jan Harm Borger, students of AOC Leeuwarden, Durk Oosterhof, Gea Zandvliet, students of Wageningen University, de Veetelers, de Boerengroep, Matthijs Witte, Hanneke Miedema, Debatcentrum Dwarsdiep Groningen, Hans Harbers, Piet van de Til, Marijke Nooijen, and the families Borren, Van de Voort, Van Tilburg, Broenink, Spruijt, De Lange, Mulder and Koekkoek. As well as to the editors and two 
anonymous reviewers. This paper presents results of the project "Ethical room for manoeuvre in livestock farming" that is funded by The Netherlands Organisation for Scientific Research (NWO) project \# 25320-013.

Open Access This article is distributed under the terms of the Creative Commons Attribution Noncommercial License which permits any noncommercial use, distribution, and reproduction in any medium, provided the original author(s) and source are credited.

\section{References}

Appleby, M. C. (2005). Sustainable agriculture is humane, humane agriculture is sustainable. Journal of Agricultural and Environmental Ethics, 18(3), 293-303.

Baars, T., \& Buitink, I. (1995). Some practical aspects of preventing disease in organic husbandry, health promotion, natural behaviour enhancement. Driebergen: Luis Bolk Instituut.

Beauchamp, T. L., \& Childress, J. F. (1994). Principles of biomedical ethics. Oxford: Oxford University Press.

Beekman, V. (2008). Consumer rights to informed choice on the food market. Ethical Theory and Moral Practice, 11, 61-72.

Birnbacher, D. (1999). Ethics and social science: Which kind of co-operation? Ethical Theory and Moral Practice, 2, 319-336.

Boltanski, L., \& Thevenot, L. (1999). The sociology of critical capacity. European Journal of Social Theory, 2(3), 359-377.

Boltanski, L., \& Thevenot, L. (2006 [1991]). On Justification, economies of worth. Princeton NJ: Princeton University Press.

Bos, A. P. (2008). Instrumentalization theory and reflexive design in animal husbandry. Social Epistemology, 22(1), 29-50.

Busch, L. (2000). The moral economy of grades and standards. Journal of Rural Studies, 16, 273-283.

Cohen, N. E., Brom, F. W. A., \& Stassen, E. N. (2009). Fundamental moral attitudes to animals and their role in judgment: An empirical model to describe fundamental moral attitudes to animals and their role in judgment on the culling of healthy animals during an animal disease epidemic. Journal of Agricultural and Environmental Ethics, 22, 341-359.

Constance, D. H. (2009). The four questions in agrifood studies: A view from the bus; the 2008 AFHVS presidential address. Agriculture and Human Values, 26, 3-14.

De Wilt, J. G., Van Oosten, H. J., \& Sterrenberg, L. (2000). Agroproductieparken: Perspectieven en dilemma's. Den Haag: Innovatienetwerk Groene Ruimte en Agrocluster.

Diamond, C. (1988). Losing your concepts. Ethics, 98, 255-277.

Driessen, C. (2007). Stacking pigs: Dutch pig tower debates and the changing nature of ethical livestock production. In W. Zollitsch, C. Winckler, S. Waiblinger, \& A. Haslberger (Eds.), Sustainable food production and ethics (pp. 219-223). Wageningen: Wageningen Academic Publishers.

Driessen, C. (2008). Ethics in the Barn; the importance of practice for agricultural ethics. Eursafe Newsletter, 10(4), 5-8.

Eshuis, J., \& Stuiver, M. (2005). Learning in context through conflict and alignment: Farmers and scientists in search of sustainable agriculture. Agriculture and Human Values, 22, 137-148.

Fraser, D. (1999). Animal ethics and animal welfare science: Bridging the two cultures. Applied Animal Behaviour Science, 65, 171-189.

Fraser, D. (2001). The "new perception" of animal agriculture: Legless cows, featherless chickens, and a need for genuine analysis. Journal of Animal Science, 79, 634-641.

Geertz, C. (2000). Available light: Anthropological reflections on philosophical topics. Princeton, NJ: Princeton University Press.

Harbers, H. (2002). Weak ethics, strong feelings. In J. Keulartz, M. Korthals, M. Schermer, \& T. Swierstra (Eds.), Pragmatist ethics for a technological culture (pp. 143-149). Deventer: Kluwer Academic Publishers.

Higgins, V. (2006). Refiguring the problem of farmer agency in agri-food studies: A translation approach. Agriculture and Human Values, 23(1), 51-62. 
Hoes, A.-C., Regeer, B., \& Bunders, J. (2008). TransFormers in knowledge production: Building sciencepractice collaborations. Action Learning: Research and Practice, 5(3), 207-220.

Jensen, K. K., \& Sørensen, J. T. (1999). The idea of 'ethical accounting' for a livestock farm. Journal of Agricultural and Environmental Ethics, 11, 85-100.

Kaiser, M., \& Forsberg, E. M. (2001). Assessing fisheries-using an ethical matrix in a participatory process. Journal of Agricultural and Environmental Ethics, 14(2), 191-200.

Keulartz, J., Korthals, M., Schermer, M., \& Swierstra, T. (Eds.). (2002). Pragmatist ethics for a technological culture. Deventer: Kluwer Academic Publishers.

Korthals, M. (2001). Ethical dilemmas in sustainable agriculture. International Journal of Food Science \& Technology, 36, 813-820.

Korthals, M. (2008). Ethical rooms for maneuver and their prospects Vis-à-vis the current ethical food policies in Europe. Journal of Agricultural and Environmental Ethics, 21, 249-273.

Kunkel, H. O. (1984). Agriculture ethics-the setting. Agriculture and Human Values, 1, 20-23.

Kupper, F., \& De Cock Buning, T. (2010). Deliberating animal values: A pragmatic-Pluralistic approach to animal ethics. Journal of Agricultural and Environmental Ethics. doi:10.1007/s10806010-9260-8.

Lamont, M., \& Thevenot, L. (2000). Rethinking comparative sociology; repertoires of evaluation in france and the United States. Cambridge: Cambridge University Press.

Law, J., \& Mol, A. (2008). Globalisation in practice: On the politics of boiling pigswill. Geoforum, 39, $133-143$.

Light, A., \& Katz, E. (Eds.). (1996). Environmental pragmatism. London: Routledge.

Marsden, T., Munton, R., Ward, N., \& Whatmore, S. (1996). Agricultural geography and the political economy approach: A review. Economic Geography, 72(4), 361-375.

McGlone, J. J. (2001). Farm animal welfare in the context of other society issues: Toward sustainable systems. Livestock Production Science, 72, 75-81.

Meijboom, F. L. B. (2009). Care and responsibility as key concepts of agricultural ethics. In K. Millar, P. H. West, \& B. Nerlich (Eds.), Ethical futures: Bioscience and food horizons (pp. 237-240). Wageningen: Wageningen Academic Publishers.

Mepham, B. (2000). A framework for the ethical analysis of novel foods: The ethical matrix. Journal of Agricultural and Environmental Ethics, 12, 165-176.

Roep, D., van der Ploeg, J. D., \& Wiskerke, J. S. C. (2003). Managing technical-institutional design processes: some strategic lessons from environmental co-operatives in the Netherlands. Netherlands Journal of Agrarian Studies, 51(1-2), 195-217.

Rollin, B. E. (1995). Farm animal welfare: Social, bioethical, and research issues. Ames: Iowa State University Press.

Rosin, C., \& Campbell, H. (2009). Beyond bifurcation: Examining the conventions of organic agriculture in New Zealand. Journal of Rural Studies, 25, 35-47.

Thompson, P. B. (1995). The spirit of the soil, agriculture and environmental ethics. London: Routledge.

Thompson, P. B. (2000). Farming as focal practice. In E. Higgs, A. Light, \& D. Strong (Eds.), Technology and the good life? (pp. 166-180). Chicago: The University of Chicago Press.

Van der Ploeg, J. D. (2003 [1999]). The virtual farmer: Past, present and future of the Dutch peasantry. Assen: Van Gorcum.

Waiblinger, S., Baars, T., \& Menke, C.(2000). Understanding the cow-The central role of humananimal relationship in keeping horned dairy cows in loose housing. In Proceedings of the 3rd workshop of the NAHWOA (Clermont-Ferrand, France, October 2000) (pp. 62-76).

Walzer, M. (1983). Spheres of justice, A defence of pluralism and equality. New York: Basic Books.

Whatmore, S. J. (2002). Hybrid geographies: Natures, cultures, spaces. London: Sage. 